\title{
Kemampuan Berpikir Kritis Siswa pada Pembelajaran Online Inquiry dan Problem Based Learning (PBL)
}

\author{
Febby Ayuni Esya Putri ${ }^{1}$, Syaiful ${ }^{2}$, Jodion Siburian ${ }^{3}$ \\ 1, 2, ${ }^{3}$ Program Studi Magister Pendidikan Matematika, Universitas Jambi \\ E-mail: holla.febby@gmail.com ${ }^{1}$, pak.bakri@unja.ac.id ${ }^{2}$, jodion.siburian@unja.ac.id ${ }^{3}$
}

\begin{abstract}
Abstrak
Penelitian ini dilatarbelakangi oleh guru yang harus tetap membantu siswauntuk mengembangkan kemampuan berpikir kritis siswa walaupun di era pandemi COVID-19. Digunakan pembelajaran online Inquiry dan PBL dengan aplikasi Zoom Cloud Meeting, sebab berdasarkan beberapa penelitian sebelumnya, pembelajaran Inquiry dan PBL dapat meningkatkan kemampuan berpikir kritis siswa. Tujuan penelitian ini adalah untuk melihat perbedaan kemampuan berpikir kritis siswa SMP pada pembelajaran online Inquiry dan PBL ditinjau dari kemampuan awal siswa, serta melihat interaksi antara pembelajaran online Inquiry dan PBL, dan kemampuan awal siswa terhadap kemampuan berpikir kritis siswa. Penelitian ini menggunakan desain quasi experimental nonequivalent control group design,dilakukan di kelas VIII SMP Negeri 7 Kota Jambi dengan menggunakan 3 kelas, yakni 2 kelas eksperimen dan 1 kelas kontrol yang dipilih dengan metode simple random sampling. Hasil penelitian diuji dengan one way dan two way ANOVA, menunjukkan terdapat perbedaan kemampuan berpikir kritis siswa berkemampuan awal tinggi, sedang dan rendah setelah diajarkan dengan pembelajaran Inquiry dan PBL, namun tidak terdapat interaksi antara pembelajaran online Inquiry dan PBL dengan kemampuan awal siswa terhadap kemampuan berpikir kritis siswa.
\end{abstract}

Kata Kunci: inkuiri, kemampuan awal siswa, kemampuan berpikir kritis, PBL, pembelajaran online

\section{Student's Critical Thinking Skill on Online Inquiry Learning and Problem Based Learning (PBL)}

\begin{abstract}
This research was motivated by teachers who must continue to help their students to enhancestudent's critical thinking skills even in COVID-19 pandemic situation. Online Inquiry and Problem Based Learning (PBL) with Zoom Cloud Meeting platform was used because based on previous research, Inquiry learning and PBL can improve student's critical thinking skills. The purpose of this study was to see the differences of junior high school student's critical thinking skills after being taught by online Inquiry learning and PBL in terms of student's initial abilities and to see the interaction between Inquiry, PBL, and initial ability with student's critical thinking. This research was used quasi experimental nonequivalent control group design, conducted in $8^{\text {th }}$ grade of Junior High School 7 Jambi City using 3 classes; 2 experimental classes and 1 control class selected by the simple random sampling method. The results of this study were tested with one way and two way ANOVA, showing that there were differences of student's critical thinking abilities with high, medium and low initial abilities after being taught by online Inquiry learning and PBL learning, but there was no interaction between online Inquiry learning and $P B L$, and student's initial ability with student's critical thinking.
\end{abstract}

Keywords:critical thinking skills, inquiry, online learning, PBL, students' initial abilities 


\section{PENDAHULUAN}

Salah satu kemampuan penting yang harus dikembangkan secara optimal oleh seseorang di abad 21 ini adalah kemampuan berpikir kritis (Crimbricz, Stoll, \& Wilkens, 2015; Trilling \& Fadel, 2009). Kemampuan berpikir kritis adalah kemampuan seseorang untuk dapat menjelaskan, menginterpretasi, meganalisis, menyimpulkan, mengevaluasi, serta self regulation (Facione, 2011; Seventika, Sukestiyarno \& Mariani, 2018). Seseorang dikatakan sudah melakukan kegiatan berpikir kritis jika sudah memenuhi indikator: (1) focus, yakni fokus terhadap permasalahan yang diberikan, (2) reason, yakni memberi alasan mengapa menggunakan suatu strategi pemecahan masalah, (3) inference, yakni memberi kesimpulan awal, (4) situation, yakni menggunakan berbagai situasi yang berkaitan untuk menyelesaikan permasalahan, (5) clarity, yakni meyakinkan apakah solusi yang diberikan sudah tepat, dan (6) overview, yakni memeriksa kembali solusi yang didapat (Ennis, 1991). Kemampuan berpikir kritis akan membantu siswa berpikir secara independen dan membantu siswa dalam menyelesaikan permasalahan dengan konteks sekolah ataupun konteks dunia nyata (Jacob, 2012). Untuk itu, kemampuan berpikir kritis adalah kemampuan yang penting untuk dimiliki oleh siswa dalam belajar matematika, dan guru harus membantu siswa mengembangkan kemampuan berpikir kritis siswa secara optimal.

Pentingnya kemampuan berpikir kritis bagi siswa ternyata belum membuat mereka mengembangkan kemampuan berpikir kritisnya secara optimal. Hal ini ditandai dengan masih rendahnya kemampuan berpikir kritis yang dimiliki siswa. Berdasarkan tes kemampuan berpikir kritis yang peneliti lakukan, hanya 13 dari 32 siswa yang nilai tes kemampuan berpikir kritisnya diatas kriteria ketuntasan minimal. Berdasarkan penelitian yang dilakukan oleh Fuad, Zubaidah, Mahanal, \& Suarsini (2017), rendahnya kemampuan berpikir kritis siswa ditandai dari belum mampunya mereka menganalisis ide atau gagasan ke arah yang lebih spesifik, belum mampu menemukan suatu gagasan dari suatu permasalahan, dan belum dapat dapat menyimpulkan suatu masalah dengan baik. Selain dari sisi siswa, rendahnya kemampuan berpikir kritis siswa juga disebabkan oleh sistem pendidikan di Indonesia yang masih memperhatikan formula pengetahuan itu sendiri tanpa mempertimbangkan konteks penerapannya dalam masyarakat, dan guru biasanya menekankan pada cara menerapkan rumus daripada membimbing mereka untuk mengembangkan kemampuan berpikir kritis siswa (Argina, Mitra, Ijabah, \& Setiawan, 2017). Berdasarkan hal yang telah dipaparkan, terlihat bahwa guru memiliki peran penting untuk mengoptimalkan kemampuan berpikir kritis siswa melalui proses pembelajaran.

Walaupun saat ini pembelajaran yang dilakukan berbasis online karena masa pandemi COVID19, tak menutup kemungkinan bagi guru untuk terus mengembangkan kemampuan berpikir kritis siswa agar lebih optimal. Guru dapat menggunakan pembelajaran yang menuntut siswa aktif dalam mengonstruksi pengetahuan yang didapatnya, yakni dengan pembelajaran berbasis Inquiry dan Problem Based Learning untuk mengembangkan kemampuan berpikir kritis siswa (Topolovčan \& Matijević, 2017). Serta, guru bisa menggunakan platform video conference seperti Zoom Cloud Meeting agar dapat mengajarkan siswa melalui mode video. Zoom menawarkan kemampuan untuk berkomunikasi secara real time dengan individu yang tersebar secara geografis melalui komputer, tablet, atau perangkat seluler (Zoom Video Communications Inc., 2016).

Pembelajaran Inquiry yang dilaksanakan dengan aplikasi Zoom Cloud Meeting dapat menjadi solusi bagi guru dalam mengoptimalkan kemampuan berpikir kritis siswa di masa pandemi seperti ini. Adapun fase-fase dari pembelajaran Inquiry yang dikembangkan oleh (Pedaste et al., 2015) yakni fase orientasi, konseptualisasi, investigasi, konklusi dan diskusi. Fase pembelajaran Inquiry yang menuntut siswa menyelesaikan masalah melalui kegiatan investigasi, dapat meningkatkan kemampuan berpikir kritis siswa melalui kegiatan menginterpretasi data dari suatu permasalahan dengan benar, dapat membuat kesimpulan dengan benar dan kontekstual, serta dapat menjelaskan serta mengevaluasi hasil dari interpretasi permasalahan (Andrini, 2016). Setelah menerapkan pembelajaran Inquiry, siswa dapat meningkatkan kinerja mereka yang berkaitan dengan kemampuan berpikir kritis seperti menginterpretasi data dari suatu permasalahan dengan benar, dapat membuat kesimpulan dengan benar dan kontekstual, dapat menjelaskan serta mengevaluasi hasil dari interpretasi permasalahan (Suryanti, Arifin, \& Baginda, 2018). 
Selain Inquiry, pembelajaran Problem Based Learning (PBL)yang dilaksanakan dengan aplikasi Zoom Cloud Meeting juga dapat menjadi solusi bagi guru dalam mendukung kemampuan berpikir kritis. Adapun tahapan pembelajaran yang terjadi pada siklus ini menurut Hmelo \& Silver (2004), yakni tahap penyajian masalah, identifikasi fakta-fakta permasalahan, menyusun hipotesis, mengumpulkan pengetahuan dari berbagai sumber dan menggunakannya untuk menyelesaikan permasalahan, serta proses abstraksi.Pembelajaran PBL yang menuntut siswa untuk menyusun informasi dari permasalahan awal yang diberikan, mengevaluasi pernyataan yang diberikan, menyimpulkan dan memvalidasi kesimpulan, ternyata dapat meningkatkan kinerja siswa yang berkaitan dengan kemampuan berpikir kritis (Arviana, Irwan, \& Dewi, 2018). Kemampuan berpikir kritis siswa yang menerima pembelajaran PBL lebih tinggi daripada siswa yang tidak menerima pembelajaran PBL (Arviana et al., 2018; Gholami et al., 2016; Widyatiningtyas, Kusumah, Sumarmo, \& Sabandar, 2015)

Adapun tujuan dari penelitian ini yaitu agar dapat melihat apakah terdapat perbedaan kemampuan berpikir kritis siswa berkemampuan awal tinggi, sedang dan rendah setelah diajarkan dengan pembelajaran Inquiry dan PBL, serta melihat apakah terdapat interaksi antara penerapan pembelajaran Inquiry dan PBLdengan kemampuan awal siswa terhadap kemampuan berpikir kritis siswa. Penelitian dilakukan untuk menentukan kebijakan dalam membantu memberi alternatif cara mengoptimalkan kemampuan berpikir kritis siswa, serta sebagai masukan dalam penggunaan pembelajaran berbasis online di masa pandemi COVID-19dengan menggunakan aplikasi Zoom Cloud Meeting.

\section{METODE}

Penelitian ini merupakan penelitian quasi-experimental, yakni individu tidak ditempatkan dalam kelompok sepenuhnya secara acak, dengan desain penelitian nonequivalent control group design,yakni membagi kelompok penelitian menjadi kelompok eksperimen dan kelompok kontrol, dan kemudian diberi pretest untuk mengetahui keadaan awal tiap kelompok yang akan diberi perlakuan dan diberi posttest setelah perlakuan (Creswell, 2012). Penelitian ini dilakukan pada bulan November 2020 dengan materi relasi dan fungsi. Populasi pada penelitian ini adalah siswa kelas VIII SMP Negeri 7 Kota Jambi, dan sampel nya yakni kelas VIII A, VIII B, dan VIII D, yang dipilih dengan teknik simple random sampling setelah populasi dinyatakan normal dan homogen. Adapun kelas VIII D merupakan kelas eksperimen I yang diajarkan dengan pembelajaran online Inquiry, kelas VIII B merupakan kelas eksperimen II yang diajarkan dengan pembelajaran online PBL, sedangkan kelas VIII A merupakan kelas kontrol yang diajarkan dengan pembelajaran langsung. Pembelajaran dilakukan secara online dengan menggunakan aplikasi Zoom Cloud Meeting.

Adapun data dalam penelitian ini adalah data tes kemampuan awal siswa yang dikumpulkan dengan instrumen pretest materi prasyarat yakni materi himpunan dan koordinat Cartesius, data keterlaksanaan proses pembelajaran yang dikumpulkan dengan instrumen lembar observasi, dan data tes kemampuan berpikir kritis siswa yang dikumpulkan dengan instrumen posttest materi relasi dan fungsi. Sebelum penelitian, instrumen divalidasi terlebih dahulu oleh satu orang ahli instrumen.Setelah didapatkan penilaian yang valid dan tidak perlu direvisi lagi, instrumen bisa digunakan untuk penelitian.

Setelah menyiapkan keperluan penelitian, peneliti memberikan pretest kepada siswa kelas eksperimen dan kelas kontrol agar diketahui kemampuan awal siswa. Setelah mendapat data hasil pretest siswa, $27 \%$ dari total siswa per kelas yang mendapat skor tertinggi dimasukkan ke kategori kemampuan awal tinggi, 27\% dari total siswa per kelas yang mendapat skor rendah dimasukkan ke kategori kemampuan awal rendah, dam sisanya dimasukkan ke kategori kemampuan awal rendah. Kemudian siswa diberi perlakuan, dan setelah itu diberi posttest kemampuan berpikir kritis. Kemudian, data dianalisis dengan menggunakan one way dan two way ANOVA dan uji lanjut (tukey). 


\section{HASIL DAN PEMBAHASAN}

\section{Hasil}

Sebelum membagi siswa berdasarkan kriteria kemampuan awal siswa, data nilai pretest diuji normalitas dan homogenitasnya. Adapun hasil normalitas data pretest siswa yang diuji dengan uji Shapir-Wilk dapat dilihat pada tabel 1.

Tabel 1. Hasil Uji Normalitas Data Pretest

\begin{tabular}{llll}
\hline & Statistic & df & Sig. \\
\hline Kelas Eksperimen I & 0.972 & 31 & 0.589 \\
Kelas Eksperimen II & 0.966 & 32 & 0.387 \\
Kelas Kontrol & 0.968 & 32 & 0.457 \\
\hline
\end{tabular}

Berdasarkan tabel 1 terlihat bahwa untuk kelas eksperimen I, kelas eksperimen II, dan kelas kontrol, nilai signifikansinya lebih besar dari 0.05 , atau dapat disimpulkan bahwa data nilai pretest untuk kelas eksperimen I, kelas eksperimen II, dan kelas kontrol berdistribusi normal.

Adapun hasil homogenitas data pretest siswa yang diuji dengan uji homogenitasdapat dilihat pada tabel 2 .

Tabel 2. Hasil Uji Homogenitas Data Pretest

\begin{tabular}{llll}
\hline Levene Statistic & df1 & df2 & Sig. \\
\hline 0.165 & 2 & 92 & 0.848 \\
\hline
\end{tabular}

Berdasarkan tabel 2 terlihat bahwa nilai signifikansinya yakni $\geq 0.05$, atau dapat disimpulkan bahwa data nilai pretest siswa memiliki variansi yang sama atau homogen.

Setelah data diuji normalitas dan homogenitasnya, langkah selanjutnya adalah membagi siswa kedalam kategori kemampuan awal tinggi sedang dan rendah. Siswa pada kelas eksperimen I yang berada pada kategori kemampuan awal tinggi, sedang dan rendah berturut-turut yakni 10, 10, dan 11 orang.Siswa pada kelas eksperimen II yang berada pada kategori kemampuan awal tinggi, sedang, dan rendah berturut-turut yakni 11, 10, dan 11 orang. Siswa pada kelas kontrol yang berada pada kategori tingi sedang dan rendah berturut-turut yakni 10, 12, dan 10 orang.

Setelah siswa dibagi kedalah kategori kemampuan awal tinggi, sedang, dan rendah, siswa diberikan perlakuan yang sama (tidak terdapat perbedaan perlakuan antara siswa berkemampuan awal tinggi, sedang, dan rendah). Siswa pada kelas eksperimen I diberikan perlakuan pembelajaran online Inquiry. Siswa pada kelas eksperimen II diberikan perlakuan pembelajaran online PBL. Serta siswa pada kelas kontrol diberikan perlakuan pembelajaran langsung secara online. Setelah diberi perlakuan, siswa diberi tes kemampuan berpikir kritis. Tes yang diberikan pun sama (tidak terdapat perbedaan perlakuan antara siswa berkemampuan awal tinggi, sedang, dan rendah).

Sebelum masuk kepada uji hipotesis, terlebih dahulu data nilai posttest diuji normalitas dan homogenitasnya sebagai prasyarat untuk uji hipotesis. Uji normalitas yang digunakan adalah uji Shapiro-Wilk. Adapun hasil uji normalitas nilai posttest siswa dapat dilihat pada tabel 3.

Tabel 3. Hasil Uji Normalitas Data Posttest

\begin{tabular}{llll}
\hline & Statistic & df & Sig. \\
\hline Kelas Eksperimen I & 0.940 & 31 & 0.082 \\
Kelas Eksperimen II & 0.940 & 32 & 0.077 \\
Kelas Kontrol & 0.960 & 32 & 0.079 \\
\hline
\end{tabular}

Pada tabel 3 terlihat bahwa untuk kelas eksperimen I, kelas eksperimen II, dan kelas kontrol, nilai signifikansi nya lebih besar dari 0.05. Maka dapat disimpulkan bahwa nilai posttest untuk kelas eksperimen I, kelas eksperimen II, dan kelas kontrol berdistribusi normal.

Setelah data diuji normalitasnya, data posttest diuji homogenitasnya. Adapun hasil uji homogenitas nilai posttest siswa dapat dilihat pada tabel 4.

Tabel 4. Hasil Uji Homogenitas Data Pretest

\begin{tabular}{llll}
\hline Levene Statistic & df1 & df2 & Sig. \\
\hline 0.218 & 2 & 92 & 0.804 \\
\hline
\end{tabular}


Berdasarkan tabel 4 terlihat bahwa nilai signifikansinya yakni $\geq 0.05$ maka data nilai posttest siswa memiliki variansi yang sama atau homogen.

Setelah dipenuhi asumsi untuk uji hipotesis, dilakukan uji ANOVA, untuk menentukan apakah rata-rata kelompok penelitian berbeda (Trihendradi, 2011). Untuk menguji hipotesis pertama digunakan uji one way ANOVA dengan hasil pengujian dapat dilihat pada tabel 5.

Tabel 5. Uji ANOVA Satu Jalur untuk Menguji Hipotesis Pertama

\begin{tabular}{llllll}
\hline \multicolumn{7}{l}{ Kelas Eksperimen I (Pembelajaran Inquiry) } & Sum of Squares & df & Mean Square & F & Sig. \\
\hline Between Groups & 6584.618 & 2 & 3292.309 & 52.736 & .000 \\
Within Groups & 1748.047 & 28 & 62.430 & & \\
Total & 8332.665 & 30 & & & \\
\hline
\end{tabular}

Pada tabel 5. terlihat bahwa nilai signifikansinya yakni $0.000(<0.05)$, maka hipotesis pertama terbukti, yakni terdapat perbedaan kemampuan berpikir kritis siswa berkemampuan awal tinggi, sedang dan rendah setelah diajarkan dengan pembelajaran Inquiry. Adapun untuk melihat perbedaannya, digunakan uji Tukey seperti pada tabel 6. berikut.

Tabel 6. Uji Tukey Kelas Eksperimen I

\begin{tabular}{lllllll}
\multicolumn{3}{c}{ Tabel 6. Uji Tukey Kelas Eksperimen I } \\
\hline $\begin{array}{l}\text { Kemampuan } \\
\text { Awal }\end{array}$ & $\begin{array}{l}\text { Kemampuan } \\
\text { Awal }\end{array}$ & $\begin{array}{l}\text { Mean } \\
\text { Difference }\end{array}$ & Std. Error & Sig. & \multicolumn{3}{c}{$\begin{array}{l}\text { 95\% Confidence } \\
\text { Interval }\end{array}$} \\
\hline \multirow{2}{*}{ Rendah } & Sedang & $-19.867^{*}$ & 3.452 & .000 & -28.41 & $\begin{array}{l}\text { Upper } \\
\text { Bound }\end{array}$ \\
& Tinggi & $-35.283^{*}$ & 3.452 & .000 & -43.83 & -26.74 \\
\multirow{2}{*}{ Sedang } & Rendah & $19.867^{*}$ & 3.452 & .000 & 11.32 & 28.41 \\
& Tinggi & $-15.417^{*}$ & 3.534 & .000 & -24.16 & -6.67 \\
\multirow{2}{*}{ Tinggi } & Rendah & $35.283^{*}$ & 3.452 & .000 & 26.74 & 43.83 \\
& Sedang & $15.417^{*}$ & 3.534 & .000 & 6.67 & 24.16 \\
\hline
\end{tabular}

*. The mean difference is significant at the 0.05 level.

Berdasarkan tabel 6 dapat dilihat bahwa setiap kategori kemampuan awal siswa memiliki perbedaan kemampuan berpikir kritis (terlihat ada tanda * pada bagian mean difference).

Untuk menguji hipotesis kedua digunakan uji one way ANOVA dengan hasil pengujian dapat dilihat pada tabel 7 .

Tabel 7. Uji ANOVA Satu Jalur untuk Menguji Hipotesis Kedua

\begin{tabular}{llllll}
\hline \multicolumn{2}{l}{ Kelas Eksperimen II (Pembelajaran PBL) } & & & \\
\hline & Sum of Squares & df & Mean Square & F & Sig. \\
\hline Between Groups & 5480.661 & 2 & 2740.331 & 34.525 & .000 \\
Within Groups & 2301.817 & 29 & 79.373 & & \\
Total & 7782.478 & 31 & & & \\
\hline
\end{tabular}

Pada tabel 7 terlihat bahwa nilai signifikansinya yakni $0.000(<0.05)$, maka hipotesis kedua terbukti, yakni terdapat perbedaan kemampuan berpikir kritis siswa berkemampuan awal tinggi, sedang dan rendah setelah diajarkan dengan pembelajaran PBL. Adapun untuk melihat perbedaannya, digunakan uji Tukey seperti pada tabel 8. 
Tabel 8. Uji Tukey Kelas Eksperimen II

\begin{tabular}{lllllll}
\hline \multirow{2}{*}{$\begin{array}{l}\text { Kemampuan } \\
\text { Awal }\end{array}$} & $\begin{array}{l}\text { Kemampuan } \\
\text { Awal }\end{array}$ & $\begin{array}{l}\text { Mean } \\
\text { Difference }\end{array}$ & Std. Error & Sig. & & \multicolumn{3}{c}{$\begin{array}{l}\text { 95\% Confidence } \\
\text { Interval }\end{array}$} \\
\hline \multirow{2}{*}{ Rendah } & Sedang & $-13.518^{*}$ & 3.893 & .005 & -23.13 & -3.90 \\
& Tinggi & $-31.470^{*}$ & 3.799 & .000 & -40.85 & -22.09 \\
\multirow{2}{*}{ Sedang } & Rendah & $13.518^{*}$ & 3.893 & .005 & 3.90 & 23.13 \\
& Tinggi & $-17.952^{*}$ & 3.893 & .000 & -27.57 & -8.34 \\
\multirow{2}{*}{ Tinggi } & Rendah & $31.470^{*}$ & 3.799 & .000 & 22.09 & 40.85 \\
& Sedang & $17.952^{*}$ & 3.893 & .000 & 8.34 & 27.57 \\
\hline
\end{tabular}

*. The mean difference is significant at the 0.05 level.

Berdasarkan tabel 8. dapat dilihat bahwa setiap kategori kemampuan awal siswa memiliki perbedaan kemampuan berpikir kritis (terlihat ada tanda * pada bagian mean difference).

Untuk menguji hipotesis ketiga digunakan uji two way ANOVA dengan hasil pengujian dapat dilihat pada tabel 9 .

Tabel 9. Uji ANOVA Dua Jalur untuk Menguji Hipotesis Ketiga

\begin{tabular}{|c|c|c|c|c|c|}
\hline Source & $\begin{array}{l}\text { Type III Sum } \\
\text { of Squares }\end{array}$ & df & $\begin{array}{l}\text { Mean } \\
\text { Square }\end{array}$ & $\mathrm{F}$ & Sig. \\
\hline Corrected Model & $17224.431^{\mathrm{a}}$ & 8 & 2153.054 & 29.907 & .000 \\
\hline Intercept & 501225.690 & 1 & 501225.690 & 6962.345 & .000 \\
\hline Pembelajaran & 579.527 & 2 & 289.764 & 4.025 & .021 \\
\hline KemampuanAwal & 16437.378 & 2 & 8218.689 & 114.163 & .000 \\
\hline $\begin{array}{l}\text { Pembelajaran * } \\
\text { KemampuanAwal }\end{array}$ & 167.766 & 4 & 41.941 & .583 & .676 \\
\hline Error & 6119.229 & 85 & 71.991 & & \\
\hline Total & 527047.500 & 94 & & & \\
\hline Corrected Total & 23343.660 & 93 & & & \\
\hline
\end{tabular}

a. R Squared $=.738$ (Adjusted R Squared $=.713$ )

Pada tabel 9. terlihat bahwa nilai signifikansinya yakni $0.676(>0.05)$, maka tidak terdapat interaksi antara penerapan pembelajaran Inquiry, PBL, dan pembelajaran langsung dengan kemampuan awal siswa terhadap kemampuan berpikir kritis siswa.

\section{Pembahasan}

Berdasarkan hasil ANOVA satu jalur yang telah dilakukan terhadap hasil posttest kemampuan berpikir kritis siswa eksperimen I yang berkemampuan awal tinggi, sedang, dan rendah setelah diajarkan dengan pembelajaran Inquiry, didapatkan hasil bawa terdapat perbedaan kemampuan berpikir kritis siswa berkemampuan awal tinggi, sedang dan rendah setelah diajarkan dengan pembelajaran Inquiry. Setiap kategori kemampuan awal siswa memiliki perbedaan kemampuan berpikir kritis. Kelompok siswa yang memiliki kemampuan awal tinggi juga memiliki nilai tes kemampuan berpikir kritis yang tinggi juga, begitu pula untuk kemampuan awal sedang dan rendah. Hal ini sesuai dengan pendapat Adams \& Bruce (1980), yakni kemampuan awal diperlukan untuk memahami kemampuan lanjutan yang lebih kompleks, sebab tanpa kemampuan awal yang mumpuni, hal yang kompleks akan sulit untuk dicapai.

Gumilar, Sunarya, \& Arifin (2017) menyatakan bahwa pembelajaran inkuiri adalah kegiatan pembelajaran di mana siswa didorong untuk belajar melalui keterlibatan aktif mereka sendiri dengankonsep-konsep dan prinsip-prinsip, dan guru mendorong siswa untuk memiliki pengalaman dan melakukan percobaan yang memungkinkan siswa menemukan prinsip-prinsip untuk diri mereka sendiri. Pada pembelajaran yang dilakukan oleh peneliti, siswa yang terlibat aktif untuk menemukan konsep pembelajaran adalah siswa dengan kemampuan awal tinggi dan sedang, sedangkan siswa dengan kemampuan awal rendah terlihat kesulitan dalam menemukan konsep pembelajaran, seperti membuat pertanyaan awal serta hipotesis, serta siswa berkemampuan awal rendah tidak terlibat aktif dalam pembelajaran dengan tidak mengaktifkan mode video pada aplikasi Zoom Cloud Meeting. Hal ini pun berdampak terhadap kemampuan berpikir kritis, karena sintaks dari pembelajaran Inquiry 
menuntut siswameningkatkan kinerja mereka yang berkaitan dengan kemampuan berpikir kritis (Suryanti, Arifin, \& Baginda, 2018). Sehingga didapatkan nilai posttest kemampuan berpikir kritis yang berbeda, yakni rata-rata kemampuan berpikir kritis siswa berkemampuan awal tinggi yakni 92.12, rata-rata kemampuan berpikir kritis siswa berkemapuan awal sedang yakni 76.70, dan rata-rata kemampuan berpikir kritis siswa berkemampuan awal rendah yakni 56.83.

Berdasarkan hasil ANOVA satu jalur yang telah dilakukan terhadap hasil posttest kemampuan berpikir kritis siswa eksperimen II yang berkemampuan awal tinggi, sedang, dan rendah setelah diajarkan dengan pembelajaran PBL, didapatkan hasil bahwa terdapat perbedaan kemampuan berpikir kritis siswa berkemampuan awal tinggi, sedang dan rendah setelah diajarkan dengan pembelajaran PBL. Setiap kategori kemampuan awal siswa memiliki perbedaan kemampuan berpikir kritis. Kelompok siswa yang memiliki kemampuan awal tinggi juga memiliki nilai tes kemampuan berpikir kritis yang tinggi juga, begitu pula untuk kemampuan awal sedang dan rendah. Hal ini sesuai dengan pendapat Adams \& Bruce (1980), yakni kemampuan awal diperlukan untuk memahami kemampuan lanjutan yang lebih kompleks, sebab tanpa kemampuan awal yang mumpuni, hal yang kompleks akan sulit untuk dicapai.

Problem Based Learning (PBL) adalah pembelajaran yang menuntut siswa secara aktif mengembangkan kemampuannya (Argaw, Haile, Ayalew, \& Kuma, 2017), yang diawali dengan pemberian permasalahan kontekstual kepada siswa, dimana permasalahan tersebut digunakan untuk memahami konsep materi yang diajarkan. Untuk menganalisis permasalahan kontekstual yang diberikan sehingga siswa memahami konsep dari materi yang diajarkan, diperlukan kemampuan berpikir kritis, sehingga pembelajaran dengan PBL akan melatih kemampuan berpikir kritis siswa. Pada pembelajaran yang dilakukan oleh peneliti, siswa yang terlibat aktif dalam proses pembelajaran adalah siswa dengan kemampuan awal tinggi dan sedang, sedangkan siswa dengan kemampuan awal rendah terlihat menemukan beberapa kesulitan dalam pembelajaran, dimana siswa tidak mampu membuat hipotesis awal serta siswa berkemampuan awal rendah tidak terlibat aktif dalam pembelajaran dengan tidak mengaktifkan mode video pada aplikasi Zoom Cloud Meeting. Hal ini pun berdampak terhadap kemampuan berpikir kritis, karena sintaks dari pembelajaran PBL dapat membimbing siswa untuk meningkatkan kinerjanya yang berkaitan dengan kemampuan berpikir kritis seperti menyusun informasi dari permasalahan awal yang diberikan, mengevaluasi pernyataan yang diberikan, menyimpulkan dan memvalidasi kesimpulan (Arviana et al., 2018). Sehingga didapatkan nilai posttest kemampuan berpikir kritis yang berbeda, yakni rata-rata kemampuan berpikir kritis siswa berkemampuan awal tinggi yakni 91.32, rata-rata kemampuan berpikir kritis siswa berkemapuan awal sedang yakni 73.73, dan rata-rata kemampuan berpikir kritis siswa berkemampuan awal rendah yakni 59.85 .

Berdasarkan hasil ANOVA dua jalur yang telah dilakukan terhadap hasil posttest kemampuan berpikir kritis siswa dan hasil kemampuan awal siswa pada kelas eksperimen dan kelas kontrol, didapatkan hasil bahwa tidak terdapat interaksi antara penerapan pembelajaran Inquiry, PBL, dan pembelajaran langsung dengan kemampuan awal siswa terhadap kemampuan berpikir kritis siswa. Hal ini dikarenakan banyak faktor lain diluar kemampuan awal yang mempunyai interaksi yang kuat dengan kemampuan berpikir kritis. Fraser, Garcia, \& Pintrinch, (1992) dalam penelitiannya mengatakan bahwa orientasi siswa terhadap tujuan dan komposisi kelas adalah faktor penting yang berinteraksi dengan kemampuan berpikir kritis. Selain itu, beberapa siswa yang tidak menghidupkan mode video pada saat pembelajaran online menggunakan Zoom Cloud Meeting merupakan salah satu faktor yang menyebabkan tidak terdapat interaksi antara kemampuan berpikir kritis dan pembelajaran online yang ditinjau dari kemampuan awal siswa.

Siswa dengan kemampuan awal tinggi memiliki minat belajar dan rasa ingin tahu yang tinggi sehingga mereka berperan aktif dalam mencari informasi baru serta membuktikan hipotesis. Sedangkan siswa dengan kemampuan awal rendah kurang aktif dalam pembelajaran, cenderung menunggu jawaban dari temannya yang lain sehingga mereka menjadi pasif dalam pembelajaran. Siswa dengan kemampuan awal rendah juga tidak mengaktifkan mode video pada saat pembelajaran online sehingga guru tidak bisa memantau kegiatan yang dilakukan siswa berkemampuan awal rendah. Siswa dengan pengetahuan awal tinggi cenderung mandiri selama proses pembelajaran, sementara siswa dengan pengetahuan awal rendah cenderung menerima struktur pembelajaran yang sudah ada 
dan susah untuk terlibat secara aktif selama proses pembelajaran (Diani, Rahayu, \& Verawati, 2019). Siswa dengan pengetahuan awal rendah mengalami kesulitan untuk terbiasa dengan sintaks model pembelajaran Inquiry dan PBL yang menuntut siswa untuk lebih mandiri dalam menemukan berbagai macam informasi baru.

\section{SIMPULAN}

Terdapat perbedaan kemampuan berpikir kritis siswa berkemampuan awal tinggi, sedang dan rendah setelah diajarkan dengan pembelajaran online Inquiry dan PBL, namun tidak terdapat interaksi antara penerapan pembelajaran Inquiry, PBL, dan pembelajaran langsung dengan kemampuan awal siswa terhadap kemampuan berpikir kritis siswa. Hal ini dikarenakan banyak faktor lain diluar kemampuan awal yang mempunyai interaksi yang kuat dengan kemampuan berpikir kritis, seperti orientasi siswa terhadap tujuan dan komposisi kelas adalah faktor penting yang berinteraksi dengan kemampuan berpikir kritis.

\section{DAFTAR PUSTAKA}

Adams, M., \& Bruce, B. C. (1980). * Center for the Study of Reading IL. (13).

Andrini, V. S. (2016). The Effectiveness of Inquiry Learning Method to Enhance Students' Learning Outcome: A Theoritical and Empirical Review. Journal of Education and Practice, 7(3), 38-42. Retrieved from https://www.semanticscholar.org/paper/The-Effectiveness-of-Inquiry-LearningMethod-to-A-Andrini/4684fdf5cf3317542b618fa20e37e39f566fb2dd

Argaw, A. S., Haile, B. B., Ayalew, B. T., \& Kuma, S. G. (2017). The Effect of Problem Based Learning (PBL) Instruction on Students' Motivation and Problem Solving Skills of Physics. Eurasia Journal of Mathematics, Science, and Technology Education, 13(3), 857-871. https://doi.org/10.12973/eurasia.2017.00647a

Argina, A. W., Mitra, D., Ijabah, N., \& Setiawan, R. (2017). Indonesia PISA Result: What Factors and What Should be Fixed? ELIC, 69-79. Retrieved from http://jurnal.unissula.ac.id/index.php/ELIC

Arviana, R., Irwan, \& Dewi, M. P. (2018). Problem Based Learning in Mathematics Education and Its Effect on Student's Problem Based Learning in Mathematics Education and Its Effect on Student's Critical Thinking. American Scientific Publishers, 24. https://doi.org/10.1166/asl.2018.11962

Creswell. (2012). Educational Research. Boston: Pearson Education Inc.

Crimbricz, S., Stoll, D., \& Wilkens, C. (2015). Developing Mathematical Thinking in the 21st Century. NYSUT's Journal of Best Practices in Education, 8. Retrieved from https://www.nysut.org/ /media/files/nysut/resources/2015/april/edvoiceviii_final.pdf?la=en

Diani, I. A., Rahayu, S., \& Verawati, N. N. S. P. (2019). Pengaruh Model Pembelajaran Berbasis Masalah dan Pengetahuan Awal Terhadap Kemampuan Berpikir Kritis Fisika Peserta Didik Kelas X. Konstan: Jurnal Fisika dan Pendidikan Fisika, 4(1), 287. Retrieved from http://jurnalkonstan.ac.id/index.php/jurnal

Ennis, R. (1991). Critical Thinking: A Streamlined Conception. Teaching Philosophy, 14(1). Retrieved from https://education.illinois.edu/docs/default-source/faculty-documents/robertennis/ennisstreamlinedconception_002.pdf

Facione, P. A. (2011). Critical Thinking: What It Is and Why It Counts. Insight Assessment, 1-28. Retrieved from https://www.insightassessment.com/CT-Resources/Teaching-For-and-AboutCritical-Thinking/Critical-Thinking-What-It-Is-and-Why-It-Counts/Critical-Thinking-What-ItIs-and-Why-It-Counts-PDF 
Fraser, B., Garcia, T., \& Pintrinch, P. R. (1992). Critical Thinking and Its Relationship to Motivation, Learning Strategies, and Classroom Experience. Contennial Annual Convention of the American Psychological Association, (1978), 1-19. Retrieved from http://www.pearweb.org/atis/documents/4/download

Fuad, N. M., Zubaidah, S., Mahanal, S., \& Suarsini, E. (2017). Improving Junior High Schools' Critical Thinking Skills Based on Test Three Different Models of Learning. International Journal of Instruction, 10(1), 101-116. https://doi.org/10.12973/iji.2017.1017a

Gholami, M., Moghadam, P. K., Mohammadipoor, F., Tarahi, M. J., Sak, M., Toulabi, T., \& Pour, A. H. H. (2016). Comparing the Effects of Problem-Based Learning and the Traditional Lecture Method on Critical Thinking Skills and Metacognitive Awareness in Nursing Students in a Critical Care Nursing Course. Nurse Education Today, 45, 16-21. https://doi.org/10.1016/j.nedt.2016.06.007

Gumilar, Sunarya, \& Arifin. (2017). Developing Chemistry Teacher's Ability to Design Inquiry-based Lab through Scaffolding type of Teacher Training Program. Journal of Physics: Conference Series, 812. https://doi.org/10.1088/1742-6596/755/1/011001

Hmelo, C. E., \& Silver. (2004). Problem-Based Learning: What and How Do Students Learn? Educational Psychology, 51(1), 31-39. https://doi.org/10.1023/B

Jacob, S. M. (2012). Mathematical Achievement and Critical Thinking Skills in Asynchronous Discussion Forums. Procedia - Social and Behavioral Sciences, 31, 800-804. https://doi.org/10.1016/j.sbspro.2011.12.144

Pedaste, M., Mäeots, M., Siiman, L. A., de Jong, T., van Riesen, S. A. N., Kamp, E. T., ... Tsourlidaki, E. (2015). Phases of Inquiry-Based Learning: Definitions and the Inquiry Cycle. Educational Research Review, 14(March), 47-61. https://doi.org/10.1016/j.edurev.2015.02.003

Seventika, S. Y., Sukestiyarno, Y. L., \& Mariani, S. (2018). Critical Thinking Analysis Based on Facione (2015) - Angelo (1995) Logical Mathematics Material of Vocational High School (VHS). Journal of Physics: Conference Series, 983(1). https://doi.org/10.1088/1742$6596 / 983 / 1 / 012067$

Suryanti, Arifin, I. S. Z., \& Baginda, U. (2018). The Application of Inquiry Learning to Train Critical Thinking Skills on Light Material of Primary School Students. Journal of Physics: Conference Series, 1108(1). https://doi.org/10.1088/1742-6596/1108/1/012128

Topolovčan, T., \& Matijević, M. (2017). Critical Thinking as a Dimension of Constructivist Learning : Some of the Characteristics of Students of Lower Secondary Education in Croatia. Center for Educational Policy Studies Journal, 7(3), 47-66. Retrieved from https://eric.ed.gov/?id=EJ1156913

Trilling, B., \& Fadel, C. (2009). 21st Century Skills. Retrieved from http://ardian.id/wpcontent/uploads/2018/10/21st_Century_Skills_Learning_for_Life_in_Our_Times__20093.pdf

Widyatiningtyas, R., Kusumah, Y. S., Sumarmo, U., \& Sabandar, J. (2015). The impact of problembased learning approach tosenior high school students' mathematics critical thinking ability. Journal on Mathematics Education, 6(2), 30-38. https://doi.org/10.22342/jme.6.2.2165.107-116

Zoom Video Communications Inc. (2016). Security guide: Zoom Video Communications Inc. Retrieved from Zoom Video Communications Inc. website: https://zoom.us/docs/doc/ZoomSecurity-White-Paper.pdf 